\title{
Detached-Leaf Method for Propagating Puccinia coronata and Assessing Crown Rust Resistance in Oat
}

\author{
E. W. Jackson and D. E. Obert, United States Department of Agriculture-Agricultural Research Service (USDA- \\ ARS) Small Grains and Potato Germplasm Research Unit, Aberdeen, ID 83210; J. Chong, Cereal Research Centre, \\ Agriculture \& Agri-Food Canada, Winnipeg, MB, Canada R3T 2M9; and J. B. Avant and J. M. Bonman, USDA- \\ ARS Small Grains and Potato Germplasm Research Unit, Aberdeen, ID
}

\begin{abstract}
Jackson, E. W., Obert, D. E., Chong, J., Avant, J. B., and Bonman, J. M. 2008. Detached-leaf method for propagating Puccinia coronata and assessing crown rust resistance in oat. Plant Dis. 92:1400-1406.

The crown rust pathogen Puccinia coronata is an obligate biotroph with wind-disseminated propagules and numerous races. These characteristics make propagation of single-race cultures difficult. Genetic studies using single races in field and greenhouse environments are also problematic because pure cultures can easily become contaminated. In this study, we developed an isolated propagation system for $P$. coronata and tested its ability to assess host resistance. Oat (Avena sativa) leaf sections (10 cm each) were harvested, disinfested, and suspended in sterile plastic boxes by enclosing $3.5-\mathrm{cm}$ linear sections of each leaf end between $4 \%$ agar blocks amended with various chemical constituents. The exposed sections (approximately $3 \mathrm{~cm}$ ) were inoculated with $P$. coronata urediniospores suspended in water. Boxes were sealed and incubated in a lighted growth cabinet until the pathogen sporulated. Viable spores were produced on leaves in all treatments, whereas 6-benzylaminopurine (BAP) and kinetin treatments sustained the leaves longer and yielded the most viable spores. Based on these data, the BAP treatment was adopted and used for additional studies. Detached leaves of differential oat cultivars produced the same reactions as whole plants screened under standard conditions in a growth chamber. The proposed detachedleaf system should be useful for the propagation of numerous single-race cultures of $P$. coronata as well as evaluation of host resistance under highly controlled conditions.
\end{abstract}

Crown rust of cultivated oat (Avena sativa L.) is caused by the obligate pathogen Puccinia coronata f. sp. avenae and is ubiquitous in most areas where oat is grown (15). Infection of oat plants is initiated when viable aeciospores or urediniospores germinate on adaxial and abaxial leaf surfaces of susceptible genotypes. Germinated spores produce appressoria that penetrate the leaf via the stomata. Once inside, a substomatal vesicle is formed, giving rise to multiple intercellular hyphae and hyphal tips. Within some of these tips, specialized haustorium mother cells are formed that give rise to haustoria (10). The intercellular branching of hyphae and production of haustoria continues, generating a colony of fungal biomass within the host tissue which, after 7 to 10 days, gives rise to sporulating uredinia

Corresponding author: E. W. Jackson

E-mail: Eric.Jackson@ars.usda.gov

* The $\boldsymbol{e}$-Xtra logo stands for "electronic extra" and indicates that Figures 1, 2, 3, and 6 appear in color in the online edition.

Accepted for publication 25 April 2008.

doi:10.1094/PDIS-92-10-1400

This article is in the public domain and not copyrightable. It may be freely reprinted with customary crediting of the source. The American Phytopathological Society, 2008.
(15). The resulting urediospores are wind disseminated and can be dispersed across long distances. For example, aeciospores or urediniospores from infected buckthorn (Rhamnus cathartica L.) and oat, respectively, can be dispersed from the northcentral United States to the eastern prairie region of Canada $(7,9,11)$ via the "Puccinia pathway." Once senescence of the host begins, teliospore formation is initiated. Teliospores are diploid, thick-walled, overwintering spores that germinate and, after meiosis, form haploid sporidia of differing mating types (26). Sporidia, better known as basidiospores, infect the alternate buckthorn host, giving rise to pycnia and pycniospores of different mating types that subsequently fuse with receptive hyphae. This fusion results in the production of aecia that produce aeciospores, which subsequently infect oat. The most important characteristic of this heteroecious disease cycle is the genetic variability produced by the meiotic recombination occurring after germination of the teliospore $(8,26)$. This recombination coupled with wind-blown dissemination has led to the presence of multiple crown rust races across large geographic areas $(7,11-$ 13,23,24). The presence of many races makes it difficult to do field experiments with oat populations segregating for resistance due to the confounding effects of multiple avirulence genes in the pathogen population. In addition, the airborne dissemination of rust pathogens such as $P$. coronata has made greenhouse propagation of single races difficult.

Characterization and mapping of complete resistance to oat crown rust is commonly based on reactions of seedlings to particular races in the greenhouse $(6,17,37)$, whereas studies to evaluate partial resistance are primarily done in the field using adult plants $(2,29,38)$. The presence of multiple races is a constant problem for both approaches, especially when infection types (ITs) vary depending on the pathogen race or when a gene confers complete resistance, masking the partial effects of other genes. To overcome this problem, Portyanko et al. (29) coupled field evaluations for partial crown rust resistance using adult plants with controlled greenhouse screening with a specific race. In addition, Jackson et al $(19,20)$ more precisely defined genetically complex crown rust resistance using artificially produced single-race field epidemics and quantitative polymerase chain reaction assessment of disease severity. These studies demonstrate the value of single-race evaluations for mapping resistance. A limitation of these studies, however, is the greenhouse and dew chamber space needed to evaluate large numbers of plants.

Production of single-race cultures of cereal rust pathogens for use in genetic studies is difficult. Propagation of $P$. coronata is currently done by inoculating susceptible plants with a desired race and incubating plants in a dew chamber under isolation to prevent contamination by propagules of other races. To purify a single race from field cultures, spores must be isolated from a single uredium and reinoculated back to an uncontaminated host plant. Unless great care is taken, single-race cultures can easily become contaminated with other races (15).

An in vitro system using detached leaves could overcome current limitations of handling single-race isolates for resistance screening and inoculum propagation. Several techniques using detached leaves have been developed to study hostpathogen interactions, including maize rust (21), Fusarium head blight of wheat (5), Septoria tritici blotch (1), yellow rust of barley (27), and powdery mildew of barley (4). Although these methods were success- 
ful, they focused on host resistance and not pathogen propagation. In addition, the only detached leaf studies on oat have been directed at the physiological aspect of metabolism, particularly respiration $(30,36)$. Maintaining healthy green leaves is critical for any detached-leaf method targeting biotrophic pathogens such as the cereal rusts. Most detached-leaf studies have utilized the cytokinin kinetin and benzimidazole to delay senescence. Two potential could be enhancement of senescence in oat by L-serine and L-cysteine in the presence of kinetin $(25,31)$ and, because benzimidazole is structurally related to the fungicide carbendazim, it may affect the production and viability of $P$. coronata propagules. To propagate single-pustule cultures and facilitate the use of single races for resistance testing, we evaluated several chemical constituents to develop a detached-leaf method suitable for use with large mapping populations.

The objectives of this study were to develop an in vitro method using detached leaves to propagate pure single-race $P$. coronata cultures and determine the feasibility of using this method to evaluate disease resistance. Using detached flag leaves maintained with the cytokinin 6benzylaminopurine (BAP), we were able to develop a detached system for $P$. coronata. The assay presented in this study provides a practical way to propagate pure single-race cultures and screen large numbers of breeding or mapping population lines for complete resistance. Future work problems with the use of these chemicals

will ascertain whether the method might also be valuable for evaluating partial resistance.

\section{MATERIALS AND METHODS}

Detached-leaf setup. Two or three oat seeds were sown in $15-\mathrm{cm}$-diameter pots containing a 1:2:1 (vol/vol/vol) mix of sand, peat moss, and vermiculite and placed in a greenhouse with a 14- to $15-\mathrm{h}$ photoperiod at 13 to $21^{\circ} \mathrm{C}$. After emergence, seedlings were thinned to one per pot and grown to heading so that fully expanded flag leaves were available for experiments. Ten-centimeter sections were harvested from the midpoint of each flag leaf, immediately disinfested for $5 \mathrm{~min}$ in $0.5 \%$ (wt/vol) $\mathrm{NaOCl}$ amended with polyoxyethylene sorbitan monolaurate (Tween) at 5 drops liter ${ }^{-1}$, and rinsed in sterile $\mathrm{H}_{2} \mathrm{O}$ for $3 \mathrm{~min}$ (3). The sections were placed in ethanol-sterilized 11-by-11-cm plastic germination boxes by sandwiching the ends of four leaves between sterile agar slabs (Fig. 1) amended with various treatments. Before sandwiching leaf ends, an additional $1 \mathrm{ml}$ of the corresponding treatment solution used to amend the agar was pipetted onto the lower slab. The plastic boxes were closed and placed in an environmentally controlled growth cabinet programmed for an 18 -h photoperiod at $21^{\circ} \mathrm{C}$.

Inoculum preparation and application. The fungal isolate used in this study, 98MNB245 (race LGCG), was obtained from the United States Department of Agriculture-Agricultural Research Service (USDA-ARS) Cereal Disease Laboratory

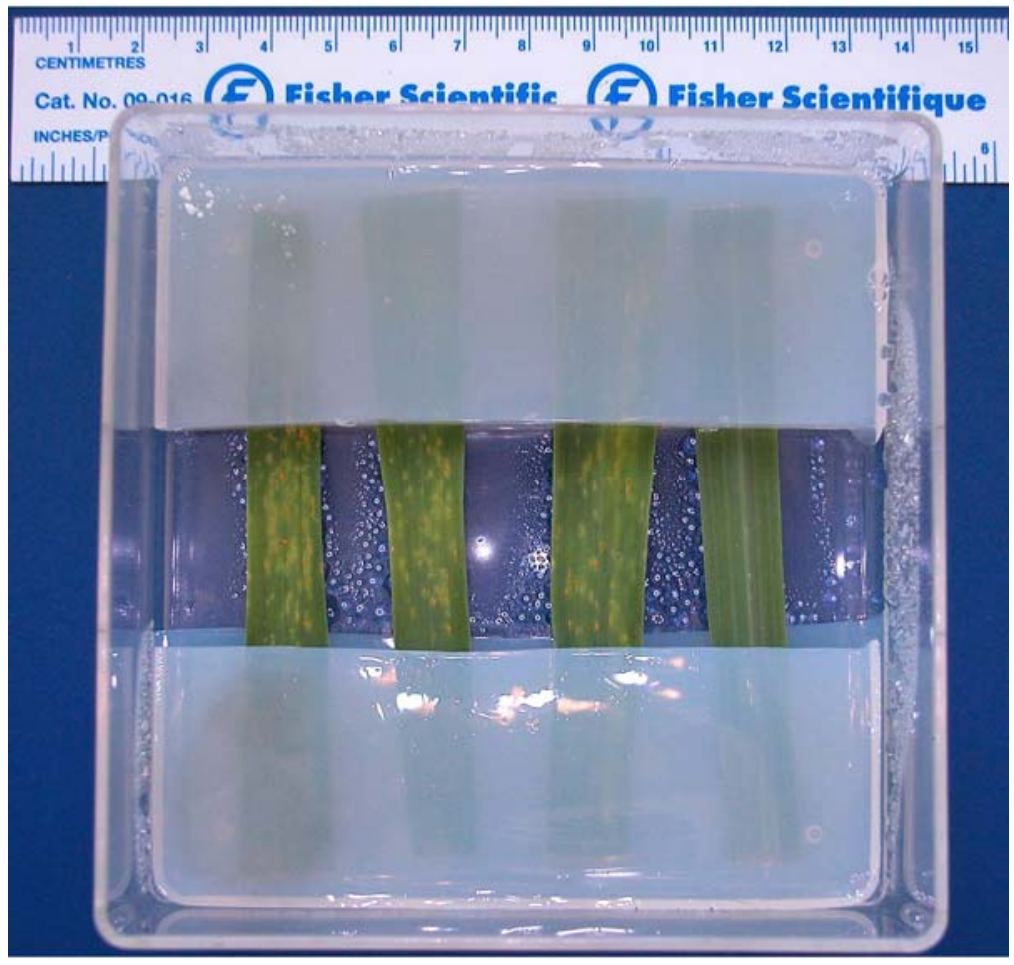

Fig. 1. Sporulation of Puccinia coronata on detached leaves 10 days after inoculation. Leaves were detached, disinfested with $0.5 \% \mathrm{NaOCl}$, placed in boxes, and three of the four leaves were inoculated in an aseptic hood using a sterile nylon tip swab applicator.
(CDL), St. Paul, MN. To increase inoculum, urediniospores previously stored at $-80^{\circ} \mathrm{C}$ (18) were suspended in the light mineral oil Soltrol 170 (Isoparaffin), heat shocked for $5 \mathrm{~min}$ at $45^{\circ} \mathrm{C}$, and sprayed onto the susceptible oat cv. Provena (14) using a spray atomizer. The inoculated plants were allowed to air dry then incubated in a dew chamber at $21^{\circ} \mathrm{C}$ in the dark for $21 \mathrm{~h}(28,32)$. Plants were then moved to a growth chamber programmed for $13 \mathrm{~h}$ of light at $25^{\circ} \mathrm{C}$ and $11 \mathrm{~h}$ of darkness at $18^{\circ} \mathrm{C}$. Approximately 10 days after inoculation, urediniospores were harvested using a vacuum collector. Spores were then vigorously agitated into a water-based suspension for use in detached-leaf assays or Soltrol 170 (Isoparaffin) for inoculations on whole plants. Concentrations were determined with a hemacytometer and adjusted to $10^{5}$ and $3 \times 10^{5}$ urediniospores $\mathrm{ml}^{-1}$ for inoculation of detached leaves and whole plants, respectively. For detachedleaf inoculations, urediniospore suspensions were applied to the middle $4 \mathrm{~cm}$ of both leaf surfaces using a sterile nylon applicator swab (Falcon), as previously described by Jackson et al. (18). This inoculation was done in an aseptic flow hood. For whole-plant inoculations, the inoculum suspension was applied using a spray atomizer as previously described.

Effect of medium amendments. Flag leaves of the susceptible oat cv. Provena were used to determine the effects of the six treatments (Table 1) on leaf longevity, spore production, germination, and infectability. To determine leaf longevity, eight detached leaves were placed in two plastic chambers (four per chamber) per treatment. Each day for 13 days, the leaves were photographed with an Olympus C7070 (3,072 by 2,304 pixels) digital camera. The amount of chlorosis was measured on a fixed $5-\mathrm{cm}^{2}$ portion of each leaf using the digital images $(n=8$ leaves/treatment/day) and the Assess image analysis software (22) with threshold settings of 103 and 60 (Fig. 2). The mean percentage of chlorosis was calculated for each treatment per day. The experiment was repeated and the data from both experiments analyzed.

The effect of each treatment on spore production, as determined by spore weight, was assessed using eight detached flag leaves of Provena ( $n=8$ leaves/treatment). Leaves were excised, disinfested, inoculated, and placed in plastic chambers. Ten days after inoculation, urediniospores from each leaf were collected in gel capsules $(n$ $=8$ gel capsules/treatment) using a minicyclone collector. Spores in gel capsules from each leaf were weighed and mean spore weights were calculated. The experiment was repeated and analysis of variance (ANOVA) was used to determine the effects of treatment, experiment, and treatment $\times$ experiment using a mixed model. The data were then analyzed for 
differences $(P<0.05)$ between treatments using the test for least significant differences (LSD; JMP, SAS Institute, Cary, NC).

Germination and infectability were assessed for spores collected from leaves of Provena subjected to each of the six detached-leaf treatments and from intact leaves of plants grown in the growth chamber. Detached leaves were inoculated as previously described and the intact plants were inoculated using a handheld spray atomizer. One day after the onset of sporulation (9 days for intact plants, 10 days for detached leaves), urediniospores were collected in a single gel capsule per leaf using a minicyclone collector. Spores from each collection were suspended in Soltrol 170 (Isoparaffin) and the concentration was adjusted to $3 \times 10^{5}$ uredinia $\mathrm{ml}^{-1}$ using a hemacytometer. The resulting inoculum suspensions from each treatment were sprayed onto four individual Provena plants at the sixth-leaf stage and four water agar plates (100 by $15 \mathrm{~mm}$ ) using a spray atomizer. The inoculated plants were air dried and placed in dew and growth chambers as previously described. Agar plates were incubated in a growth cabinet at $21^{\circ} \mathrm{C}$ overnight. Each plate was divided into four quadrants and 100 spores/quadrant were examined $12 \mathrm{~h}$ after inoculation at $\times 40$ magnification to assess germination (Fig. $3)$. To determine infectability, $5-\mathrm{cm}^{2} \mathrm{sec}-$ tions from the midpoint of the fifth leaves from the four inoculated Provena plants were harvested. The sections were scanned at 118 dots $\mathrm{cm}^{-1}$ and diseased leaf area (DLA) and pustule density (number of pustules $/ \mathrm{cm}^{2}$ ) were calculated using the Assess image analysis software (22) with threshold settings of 103 and 60 for DLA and 103 and 90 for pustule density. The experiment was repeated and the mean percent germination, DLA, and pustule density were calculated. ANOVA was used to calculate the effects of treatment, inoculum source, experiment, treatment $\times$ inoculum source, treatment $x$ experiment, inoculum source $x$ experiment, and treatment $x$ inoculum source $x$ experiment using a mixed model. Differences $(P<0.05)$ were then determined between treatments for germination and infectability using LSD (JMP, SAS Institute).
Resistance test. Flag leaves of the 16 North American oat crown rust differentials (12) were used to evaluate the ability of the detached-leaf method to measure complete (major gene) resistance. Leaf sections from eight plants were detached, disinfested, inoculated with an isolate of race LGCG, and suspended on agar amended with BAP. After 10 days, images were captured with a digital camera. In the first experiment, leaf sections were inoculated with a nylon swab as previously described whereas, in the second experiment, four $10-\mu l$ inoculum drops were placed on each leaf section following placement in the chambers. For comparison with the detached methods in both experiments, heading plants were spray inoculated as previously described and, after 10 days, the fifth leaf was detached and scanned from each differential $(n=8)$. Direct comparisons of ITs were made between detached and intact leaf images for each differential and experiment.

\section{RESULTS}

Leaf longevity. Clear effects of treatments on the percentage of chlorotic area
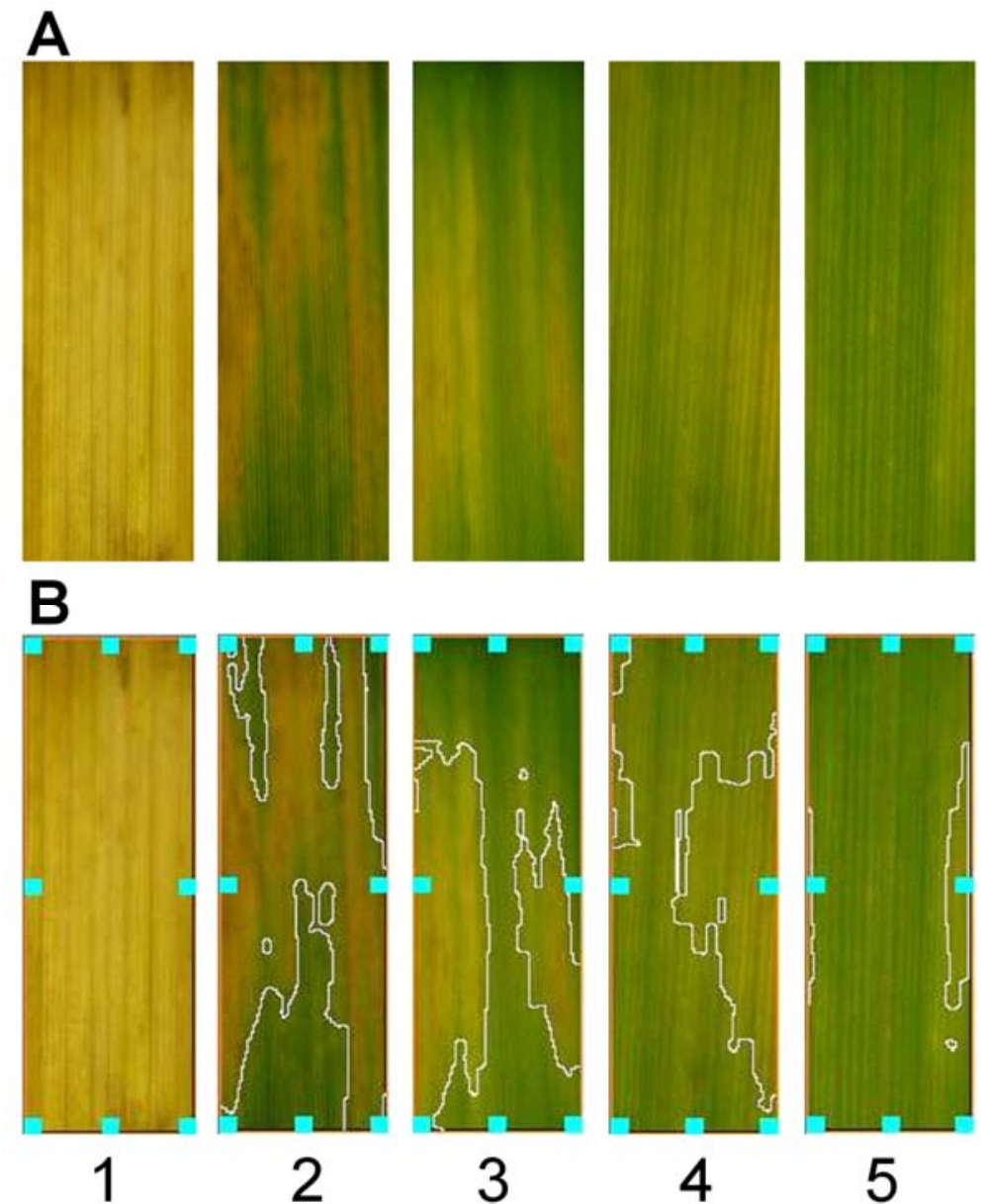

Fig. 2. Oat leaves 10 days after excision. A, Detached leaves were maintained on agar (1), agar amended with 6-benzylaminopurine (BAP) mix (2), nutrient mix (3), benzimidazole (4), kinetin (5), and BAP (6). B, Mean percent chlorotic areas were calculated using the Assess imagine analysis software. Chlorotic areas on each detached leaf (left to right) were $100 \%$ for agar, $72.3 \%$ for BAP mix, $44.2 \%$ for nutrient mix, $41.4 \%$ for Benzimidazole, $9.5 \%$ for Kinetin, and $0.0 \%$ for BAP.

Table 1. Agar treatments ${ }^{\mathrm{z}}$

\begin{tabular}{|c|c|}
\hline Designation & Chemical and concentration \\
\hline $\mathrm{N}^{6}$-benzylaminopurine (BAP) & 6-Benzylaminopurine at $100 \mathrm{mg} /$ liter \\
\hline Kinetin & Kinetin at $100 \mathrm{mg} /$ liter \\
\hline Benzimidazole & Benzimidazole at $100 \mathrm{mg} /$ liter \\
\hline Nutrient mix & $\begin{array}{l}\text { Kinetin, } 10 \mathrm{mg} / \text { liter + zeatin, } 10 \mathrm{mg} / \text { liter + benzimidazole, } 10 \mathrm{mg} / \text { liter + sucrose, } 2 \mathrm{~g} / \mathrm{liter}+\left(\mathrm{NH}_{4}\right)_{2} \mathrm{SO}_{4}, 0.463 \mathrm{~g} / \mathrm{liter}+ \\
\mathrm{KNO}_{3}, 2.83 \mathrm{~g} / \mathrm{liter}+\mathrm{KH}_{2} \mathrm{PO}_{4}, 0.4 \mathrm{~g} / \mathrm{liter}+\mathrm{MgSO}_{4}(7 \mathrm{H} \mathrm{H}), 0.185 \mathrm{~g} / \mathrm{liter}+\mathrm{CaCl}_{2}(2 \mathrm{H} \mathrm{H}), 0.166 \mathrm{~g} / \mathrm{liter}+ \\
\mathrm{FeSO}_{4}, 0.040 \mathrm{~g} / \mathrm{liter}+\text { glycine, } 0.2 \mathrm{~g} / \text { liter + thiamine, } 0.1 \mathrm{~g} / \mathrm{liter}+\text { pyridoxinem, } 0.05 \mathrm{~g} / \mathrm{liter}+\text { nicotinic acid, } 0.05 \mathrm{~g} / \mathrm{liter}\end{array}$ \\
\hline BAP mix & $\begin{array}{l}\mathrm{N}^{6} \text {-benzylaminopurine, } 100 \mathrm{mg} / \mathrm{liter}+\text { benzimidazole, } 10 \mathrm{mg} / \text { liter }+ \text { sucrose, } 2 \mathrm{~g} / \mathrm{liter}+\left(\mathrm{NH}_{4}\right)_{2} \mathrm{SO}_{4}, 0.463 \mathrm{~g} / \mathrm{liter}+\mathrm{KNO}_{3} \text {, } \\
2.83 \mathrm{~g} / \mathrm{liter}+\mathrm{KH}_{2} \mathrm{PO}_{4}, 0.4 \mathrm{~g} / \mathrm{liter}+\mathrm{MgSO}_{4}\left(7 \mathrm{H}_{2} \mathrm{O}\right), 0.185 \mathrm{~g} / \mathrm{liter}+\mathrm{CaCl}_{2}\left(2 \mathrm{H}_{2} \mathrm{O}\right), 0.166 \mathrm{~g} / \mathrm{liter}+\mathrm{FeSO}_{4}, 0.040 \mathrm{~g} / \mathrm{liter}+ \\
\text { glycine, } 0.2 \mathrm{~g} / \text { liter }+ \text { thiamine, } 0.1 \mathrm{~g} / \mathrm{liter}+\text { pyridoxine, } 0.05 \mathrm{~g} / \mathrm{liter}+\text { nicotinic acid, } 0.05 \mathrm{~g} / \mathrm{liter}\end{array}$ \\
\hline Agar & No amendments \\
\hline
\end{tabular}

${ }^{\mathrm{z}}$ Chlorothalonil at $10 \mathrm{mg} /$ liter was added to each treatment to suppress fungal contamination on agar. 
were observed (Fig. 2). In the first experiment, chlorosis was first observed 3 days after detachment (DAD) on leaves maintained with the BAP mix, while chlorosis was observed 4 DAD on leaves maintained with the agar (control) and the nutrient mix (Fig. 4A). Between 4 and 5 DAD, a large increase in the amount of chlorosis was observed on leaves maintained using all three treatments. This trend continued on leaves maintained with agar until day 7 , when leaves were completely chlorotic. In contrast, leaves maintained on both tissue culture mixes progressed much more slowly after day 5, not becoming completely chlorotic until day 13 (Fig. 4A). The first signs of chlorosis did not appear on leaves maintained with benzimidazole or kinetin until 6 DAD. For both treatments, chlorosis progressed slowly until day 12 , where a sharp increase in chlorosis was observed on leaves maintained with benzimidazole (Fig. 4A). Less than $10 \%$ of the leaf areas maintained using BAP were chlorotic even 13 DAD. In the second experiment, the onset of chlorosis was delayed 3 to 5 days compared with the first experiment. Similar to the first experiment, leaves maintained with agar were completely chlorotic first, whereas chlorosis on leaves maintained with both tissue culture

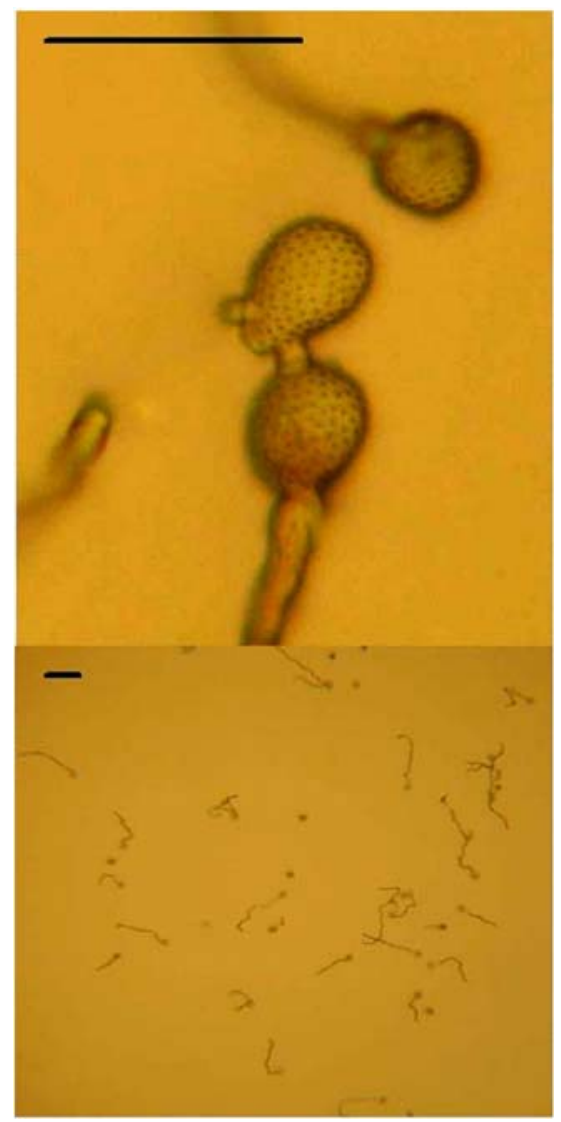

Fig. 3. Urediniospores collected from detached leaves 10 day after inoculation. Spores were suspended in Soltrol 170 (Isoparaffin) and sprayed onto $2 \%$ water agar. Spores were visualized after $12 \mathrm{~h}$ using a compound microscope at $\times 5$ (bottom) and $\times 40$ (top). mixes and benzimidazole increased sharply $9 \mathrm{DAD}$, and chlorosis of leaves maintained with kinetin and BAP was considerably less overall (Fig. 4B).

Spore production. The only experimental effect $(P<0.05)$ measured was for the treatment variable; therefore, combined spore weights from repeated experiments were used to determine differences between treatments. More spores $(P<0.05)$, as determined by weight, were collected from leaves maintained on BAP and kinetin than from the other treatments (Fig. 5 ). Of the remaining treatments, no spores

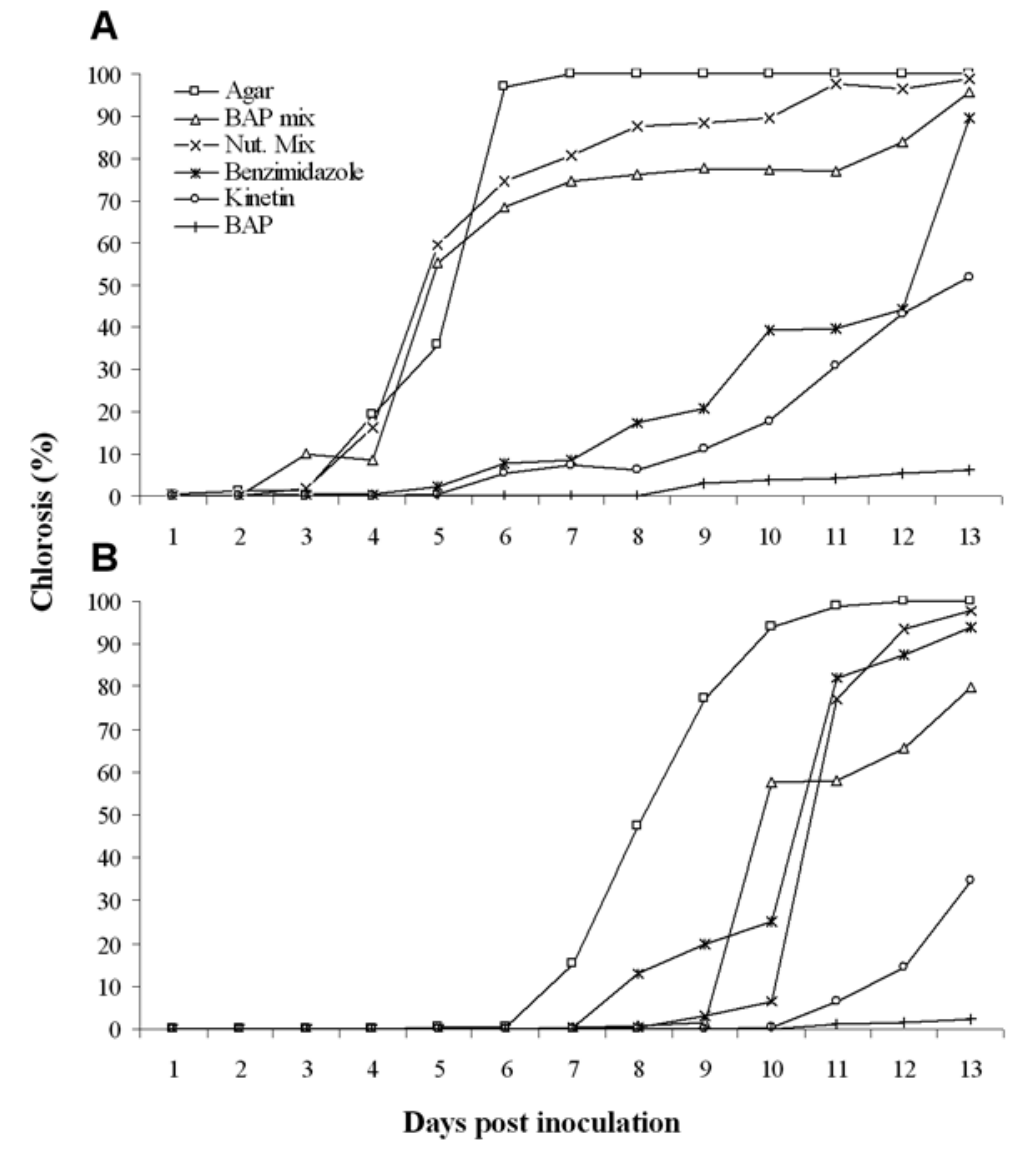

Fig. 4. A and B, Mean percentage of chlorosis on detached leaves maintained on agar amended with six different chemical constituents over 13 days in a repeated experiment.

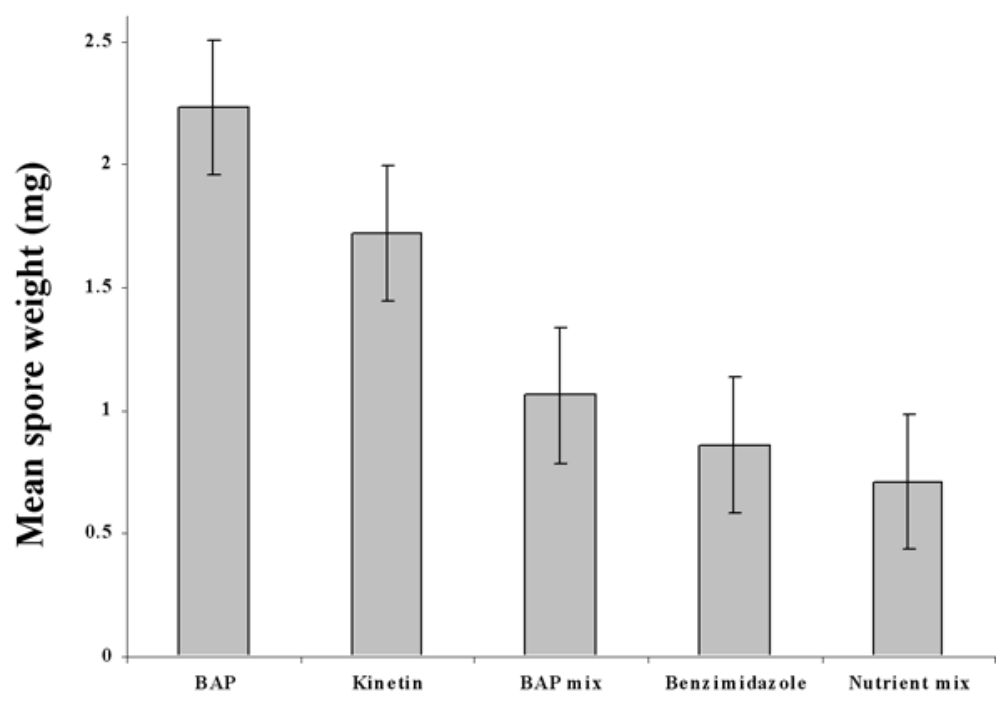

Agar amendment

Fig. 5. Combined mean Puccinia coronata spore weights from two experiments for spores collected from eight detached oat leaves maintained on agar amended with five treatments and a no-treatment control. Bars indicate least significant difference $(P<0.05)$. 
$(P<0.05)$ were collected from leaves maintained on unamended agar compared with leaves maintained on the BAP mix or benzimidazole (data not shown). No differences in spore weights $(P<0.05)$ were found between leaves maintained with the nutrient mix, BAP mix, benzimidazole, or agar (Fig. 5).

Spore germination and infectability. Effects were observed for treatment, experiment, treatment $\times$ experiment, and treatment $x$ inoculum source $x$ experiment $(P>0.05)$ for both germination and infectability. Additionally, there was an effect of inoculum source $(P=0.044)$ on infectability. Based on these results, differences between treatments for both measurements were determined within each experiment. For germination, no differences $(P>0.05)$ were observed in the first experiment among spores collected from leaves maintained with BAP, the intact host, benzimidazole, the nutrient mix, or kinetin treatments; however, germination was higher $(P>0.05)$ from these treatments than from the BAP mix or the agar control (Table 2). In the second experiment, germination of spores collected from the live host was greater than spores from detached leaves. Of the spores produced on detached leaves, germination was greater $(P<0.05)$ from leaves maintained on benzimidazole and BAP compared with the other treatments (Table 2). The lowest percent germination in the second experiment was from spores from leaves maintained on the nutrient mix, BAP mix, and the agar control (Table 2).

In the first experiment, infectability was highest for spores produced on the intact plant and the kinetin and BAP treatments. Detached leaves maintained on BAP mix produced spores with the lowest infectability (Table 2). The second experiment produced similar results except that spores from the BAP treatment showed lower infectability relative to spores from the intact plant.

Resistance test. Among the 16 oat crown rust differentials (12), immune reactions (no symptom) were observed on detached and intact leaves of the differentials with genes $P c 45, P c 48, P c 52$, and Pc68 (Fig. 6). Low ITs with chlorotic and necrotic flecks (;), tiny pustules surrounded by chlorotic and necrotic areas, (;1), and slightly bigger pustules with or without chlorotic or necrotic areas around them (1-2) were observed on detached and intact leaves of the differentials with $P c 38$, Pc46, Pc50, Pc51, Pc54, Pc58, Pc59, $P c 62$, and $P c 64$ genes. Large pustules were observed on the differentials with Pc39, Pc40, and Pc56 (Fig. 6). Infection types found on the intact plants of all 16 differentials were either identical or very similar to those on the detached leaves of the differentials.

\section{DISCUSSION}

All five agar amendments retarded $(P>$ $0.05)$ chlorosis compared with the agar control, and the treatment with BAP alone was the most effective. The presence of the added constituents clearly reduced its effectiveness because the concentration of BAP was the same whether it was alone or in a mix. Although leaf senescence was generally slower in the second experiment, in both experiments the tissue culture mixes and benzimidazole were much less effective than either of the cytokinins.

In all, 7 to 10 days are required for initial sporulation of crown rust (15); thus, maintaining green detached leaves for much longer periods is essential to propagate the fungus. In previous reports, detached wheat and barley leaves were kept green for 14 to 34 days on benzimidazole agar $(1,27)$ and detached wheat leaves

Table 2. Mean germination and infectability of Puccinia coronata urediniospores collected from intact oat leaves and detached oat leaves maintained on agar amended with five different chemical constituents and a no-treatment control in repeated experiments ${ }^{\mathrm{w}}$

\begin{tabular}{lccccc}
\hline & \multicolumn{2}{c}{ Experiment 1 } & & \multicolumn{2}{c}{ Experiment 2 } \\
\cline { 2 - 3 } \cline { 5 - 6 } Treatments $^{\mathbf{x}}$ & ${\text { Germination }(\%)^{\mathbf{y}}}$ & Infectability $^{\mathbf{z}}$ & & ${\text { Germination }(\%)^{\mathbf{y}}}^{\text {Infectability }^{\mathbf{z}}}$ \\
\hline BAP & $70.3 \mathrm{~A}$ & $7.4 \mathrm{~A}$ & & $57.3 \mathrm{BC}$ & $7.8 \mathrm{~B}$ \\
Intact plant (control) & $67.3 \mathrm{~A}$ & $8.3 \mathrm{~A}$ & & $84.5 \mathrm{~A}$ & $10.7 \mathrm{~A}$ \\
Benzimidazole & $67.0 \mathrm{~A}$ & $5.5 \mathrm{~B}$ & & $64.5 \mathrm{~B}$ & $2.7 \mathrm{C}$ \\
Nutrient mix & $64.8 \mathrm{~A}$ & $5.2 \mathrm{~B}$ & & $25.0 \mathrm{E}$ & $2.8 \mathrm{C}$ \\
Kinetin & $62.8 \mathrm{~A}$ & $7.8 \mathrm{~A}$ & & $42.8 \mathrm{CD}$ & $9.1 \mathrm{AB}$ \\
BAP mix & $45.8 \mathrm{C}$ & $2.3 \mathrm{C}$ & & $32.3 \mathrm{DE}$ & $4.2 \mathrm{C}$ \\
Agar (control) & $40.8 \mathrm{C}$ & $5.7 \mathrm{~B}$ & & $32.5 \mathrm{DE}$ & $4.1 \mathrm{C}$ \\
LSD $(P=0.05)$ & 9.0 & 1.5 & & 14.9 & 1.6 \\
\hline
\end{tabular}

${ }^{\mathrm{w}}$ Means within the same column followed by the same letter are not different $(P<0.05)$.

${ }^{x}$ Spore collections were made 1 day after the onset of sporulation from pustules on intact leaves of plants grown in the growth chamber and detached leaves maintained in a lighted cabinet on agar with various chemical constituents. Inoculum preparations were made from intact or detached leaves of two individual plants per experiment. $\mathrm{BAP}=\mathrm{N}^{6}$-benzylaminopurine and LSD $=$ least significant difference.

${ }^{y}$ Mean percent germination was based on the number of urediniospores on $2 \%$ water agar with germ tubes out of 100 from four replicate counts of two independent inoculum preparations per experiment.

${ }^{\mathrm{z}}$ Mean infectability for each experiment was based on the number of pustules $/ \mathrm{cm}^{2}$ on 'Provena' $(n=$ 4) leaves 10 days after inoculation with two independent inoculum preparations per treatment. were kept green for at least 14 days using kinetin (5). In the present study, only the kinetin and BAP treatments retarded chlorosis up to 10 days, and very little chlorosis was observed when using BAP up to 13 days. Thus, the synthetic cytokinin BAP was considerably more effective at slowing the rate of chlorosis of detached oat leaves than benzimidazole and kinetin. This finding is consistent with previous reports which indicated that BAP is five times more active than kinetin at suppressing respiratory rise and subsequent senescence in detached oat leaves (36). One possible reason for the increased activity of BAP over kinetin could be the enhanced mobility of BAP into detached leaves (W. R. Bushnell, personal communication).

The amount, viability, and infectability of spores produced are critical to the use of an in vitro system to propagate single-race cultures of $P$. coronata. In this study, the superior production of spores on leaves maintained with BAP and kinetin could be directly attributed to overall leaf health as measured by lack of chlorosis. Sporulation was not observed until 7 to 10 days after inoculation, a time period corresponding to an increase $(P<0.05)$ of chlorosis as measured on detached leaves maintained with tissue culture mixes, benzimidazole, and the agar control. P. coronata is an obligate biotroph that uses intercellular hyphae and haustorium to acquire nutrients from living hosts $(15,33,34)$; thus, it is probable that a reduction in nutrients due to leaf senescence would translate into less sporulation.

Spore germination was not reduced compared with spores from intact plants when using BAP, benzimidazole, kinetin, or the nutrient mix in the first experiment. In the second experiment, all the treatments produced fewer $(P>0.05)$ spores that germinated compared with spores formed on intact leaves. The overall mean germination of spores produced in the second experiment on all treatments was reduced by $16.2 \%$ from the first experiment, whereas germination of spores from the intact plants increased by $17.2 \%$. Additionally, much greater variability in germination was observed in the second experiment. The most probable reason for the decrease in germination and increase in variability was due to premature germination of spores within the pustule on detached leaves in the presence of abundant free moisture inside a sealed chamber. During collection, germ tubes of germinated spores could break off, thus appearing to not have germinated when examined. Even in the second experiment, the detached leaves maintained with BAP, kinetin, and benzimidazole all produced enough viable spores for further propagation of the isolate. However, reducing the amount of humidity within the detached system by providing filtered air movement might improve viability and consistency. 
Additionally, humidity could be reduced by either limiting the application or not applying liquid media between agar pieces. Preliminary data from the Cereal Research Centre, Winnipeg, Canada indicates that having no treatment solution between the agar slabs enhanced leaf longevity, and future work will aim to confirm this initial observation.

The infectability of spores collected from detached leaves maintained on BAP and kinetin was similar to that of spores collected from intact plants. In contrast, spores collected from detached leaves maintained by the two tissue culture mixes, benzimidazole, and agar produced relatively lower amounts of disease. Reduced infectability of spores collected from leaves maintained with the agar control and the tissue culture mixes was expected in both experiments because of the
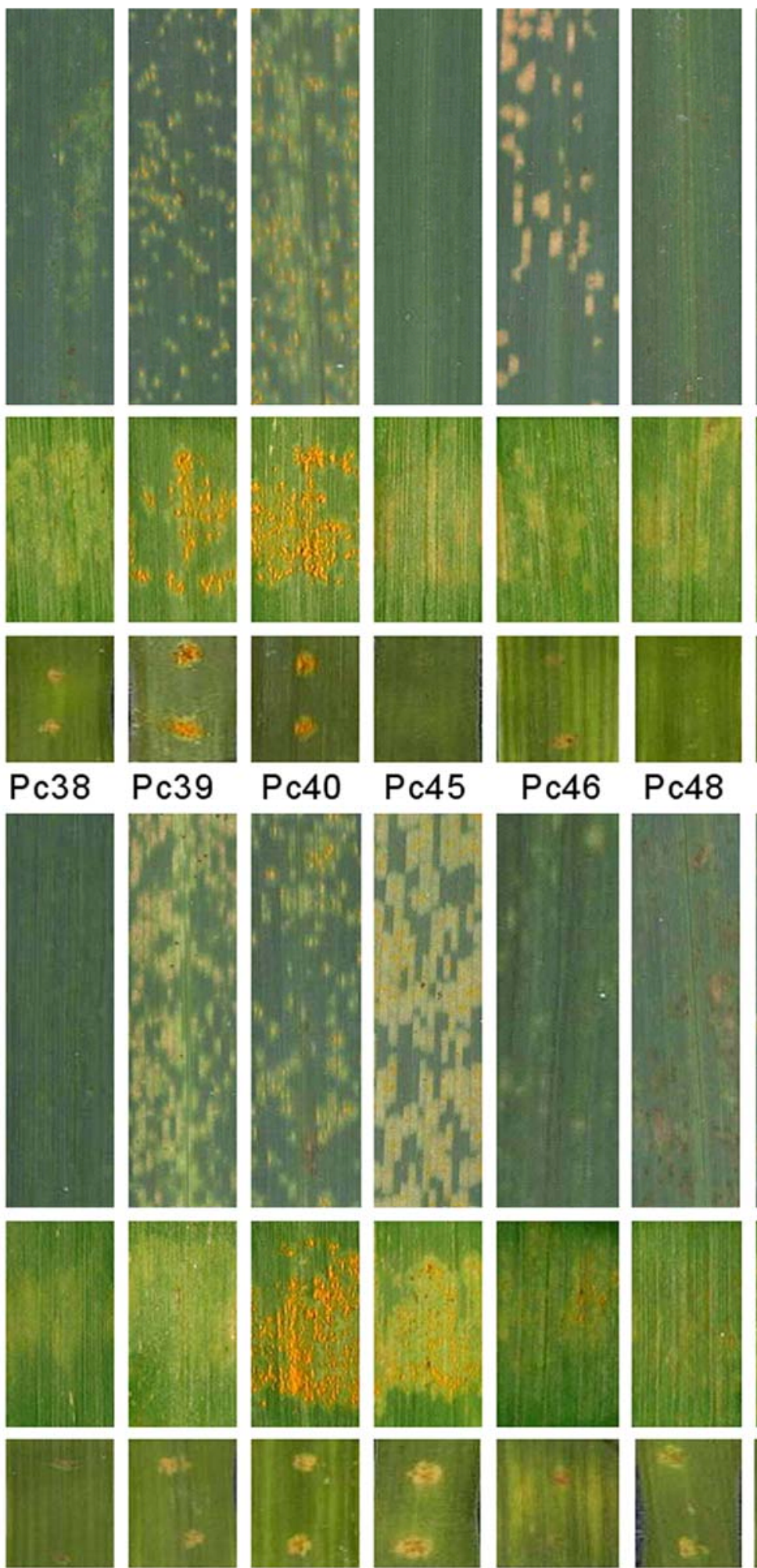

$\mathrm{Pc5} 2$
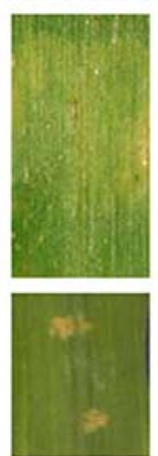

Pc54
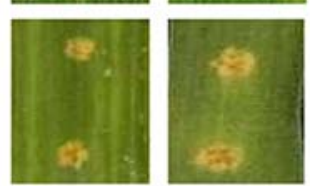

Pc56 Pc58

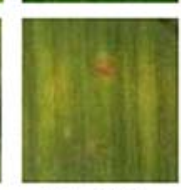

Pc59

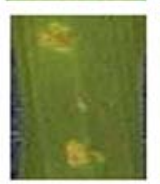

Pc62
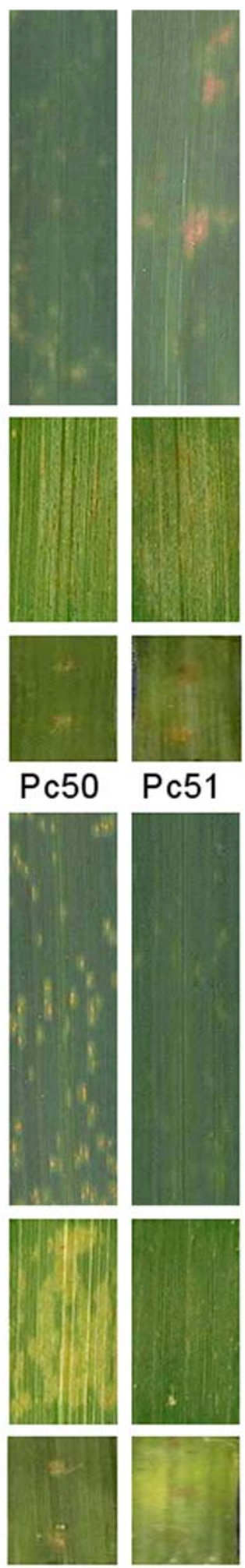

Pc64 Pc68

Fig. 6. Reactions of 16 differential oat cultivars 12 days after inoculation with Puccinia coronata isolate $98 \mathrm{MNB} 245$. Plants were inoculated with $10^{5}$ urediniospores/ml using three different methods. Intact flag leaves were spray inoculated using standard greenhouse methods (top plates). Detached flag leaves were swab inoculated (middle plate) and inoculated with $5-\mu l$ droplets using a micropipette (bottom plate). 
extensive leaf chlorosis (100\%) at the time of spore harvest (10 days). However, the reduced infectability of spores from leaves maintained by benzimidazole was unexpected. In a previous study using Colletotrichum spp., Takano et al. (35) showed that, although conidia germinated after treatment with benzimidazole, the germ tubes differentiated into swollen appressoria which curled upon themselves. Curling was attributed to the disruption of microtubules caused by the benzimidazole treatment. In addition, an abundance of microtubules was located in the apex of Uromyces phaseoli var. typica germlings near the germ tube-host interface after treatment with benzimidazole (16). It is plausible that benzimidazole had a similar effect in this study, disrupting microtubule formation during infection structure development and, thus, reducing infectability.

There were no differences in IT between intact and detached leaves of all 16 differentials when inoculated with isolate 98MNB245. This indicated that the detached-leaf method is also suitable for genetic studies of host resistance. Isolate 98MNB245 was identified to be race LGCG at the CDL, where it produced high ITs on the $P c 39,-40,-56$, and -59 differentials (Dr. Marty Carson, personal communication). In our study with intact and detached leaves of the same 16 differentials, the isolate was initially identified to be race LGBG because it was avirulent to Pc59. This discrepancy was due to seed admixture known to be present in several differentials, including Pc59. The seed of the 16 differentials used in this study was originally obtained from the CDL and was propagated before use. Because of the discrepancy in reaction of isolate $98 \mathrm{MNB} 245$ to $P c 59$, we have subsequently used the detached-leaf method as a way to nondestructively purify our seed. We inoculated the fifth leaves of eight individual plants for each differential line with isolate 98MNB245 along with an additional single-pustule isolate, 03MN111 (race NQMG), obtained from the CDL. We kept only those plants that produced appropriate ITs according to the race designation identified at the CDL. Seed was then harvested from the remaining plants and used in subsequent single-isolate race studies by Jackson et al. (20), in which the reactions of the isolates on the 16 "purified" differential lines matched the race designation previously assigned to each isolate.

\section{ACKNOWLEDGMENTS}

We thank I. Shackelford, K. Satterfield, and K. Brown for their technical expertise in laboratory and greenhouse experiments; and W. R. Bushnell (retired) and M. Carson from the USDA-ARS CDL, St. Paul, MN, for their technical help with this project.

\section{LITERATURE CITED}

1. Arraiano, L. S., Brading, P. A., and Brown, J. K. M. 2001. A detached seedling leaf tech- nique to study resistance to Mycosphaerella graminicola (anamorph Septoria tritici) in wheat. Plant Pathol. 50:339-346.

2. Barbosa, M. M., Federizzi, L. C., Milach, S. C. K., Martinelli, J. A., and Thome, G. C. 2006. Molecular mapping and identification of QTLs associated to oat crown rust partial resistance. Euphytica 150:275-269.

3. Brown, E. A., Minor, H. C., and Calvert, O. H. 1987. A soybean genotype resistant to Phomopsis seed decay. Crop Sci. 27:895-898.

4. Brown, J. K. M., and Wolfe, M. S. 1990. Structure and evolution of a population of Erysiphe graminis f. sp. hordei. Plant Pathol. 39:376390.

5. Browne, R. A., and Cooke, B. M. 2004. Development and evaluation of an in vitro detached leaf assay for pre-screening resistance to Fusarium head blight in wheat. Eur. J. Plant Pathol. 110:91-102.

6. Bush, A. L., and Wise, R. P. 1998. Highresolution mapping adjacent to the Pc71 crown-rust resistance locus in hexaploid oat. Mol. Breed. 4:13-21.

7. Chong, J. 2000. Incidence and virulence of Puccinia coronata f. sp. avenae in Canada from 1996 to 1998. Can. J. Plant Pathol. 22:99-109.

8. Chong, J. 2003. Diseases of oat. Pages 74-88 in: Diseases of Field Crops in Canada. K. L. Bailey, B. D. Gossen, R. K. Gugel, and R. A. A. Morrall, eds. Canadian Phytopathological Society, ON, Canada.

9. Chong, J., Gruenke, J., Dueck, R., Mayert, W., and Woods, S. 2008. Virulences of oat crown rust in Canada during 2002-2006. Can. J. Plant Pathol. 30:115-123.

10. Chong, J., and Harder, D. E. 1982. Ultrastructure of haustorium development in Puccinia coronata f. sp. avenae: cytochemistry and energy dispersive X-ray analysis of the haustorial mother cells. Phytopathology 72:1518-1526.

11. Chong, J., and Kolmer, J. A. 1993. Virulence dynamics and phenotypic diversity of Puccinia coronata f. sp. avenae in Canada during 19741990. Can. J. Plan Pathol. 71:248-255.

12. Chong, J., Leonard, K. J., and Salmeron, J. J. 2000. A North American system of nomenclature for Puccinia coronata f. sp. avenae. Plant Dis. 84:580-585.

13. Chong, J., and Zegeye, T. 2004. Physiologic specialization of Puccinia coronata f. sp. avenae, the cause of oat crown rust, in Canada from 1999 to 2001. Can. J. Plant Pathol. 26:97-108.

14. Erickson, C. E., Wesenberg, D. E., Whitmore, J. C., and Marshall, H. G. 2003. Registration of 'Provena' oat. Crop Sci. 43:2301.

15. Harder, D. E., and Haber, S. 1992. Oat diseases and pathogenic techniques. Pages 307425 in: Oat Science and Technology. H. G. Marshall and M. E. Sorrells, eds. American Society of Agronomy and Crop Science Society of America, Madison, WI.

16. Hoch, J. C., and Staples, R. C. 1983. Ultrastructural organization of the nondifferentiated uredospores germling of Uromyces phaseoli variety typica. Mycologia 75:795824.

17. Hoffman, D. L., Chong, J., Jackson, E. W., and Obert, D. E. 2006. Characterization and mapping of a crown rust gene complex (Pc58) in TAM O-301. Crop Sci. 46:2630-2635.

18. Jackson, E. J., Avant, J. B., Overturf, K. E., and Bonman, J. M. 2006. A quantitative assay of Puccinia coronata f. sp. avenae DNA in Avena sativa. Plant Dis. 90:629-636.

19. Jackson, E. J., Obert, D. E., Menz, M., Hu, G., Avant, J. B., and Bonman, J. M. 2007. Characterization and mapping oat crown rust resistance using three assessment methods. Phytopathology 97:1063-1070.

20. Jackson, E. W., Obert, D. E., Menz, M., Hu, G., and Bonman, J. M. 2007. Qualitative and quantitative trait loci conditioning resistance to Puccinia coronata pathotypes NQMG and LGCG in the oat (Avena sativa L.) cultivars Ogle and TAM O-301. Theor. Appl. Genet. 116:517-527.

21. Kushalappa, A. C., and Hegde, R. K. 1971. Studies on maize rust Puccinia sorghi in mysore state I. effect of temperature on urediospores germination on water agar and detached host leaf. Indian Phytopathol. 24:759764.

22. Lamari, L. 2002. Assess Image Analysis Software for Plant Disease Quantification. American Phytopathological Society, St Paul, MN.

23. Leonard, K. J. 2003. Regional frequencies of virulence in oat crown rust in the United States from 1990 through 2000. Plant Dis. 87:13011310 .

24. Leonard, K. J., Anikster, Y., and Manisterski, J. 2004. Patterns of virulence in natural populations of Puccinia coronata on wild oat in Israe and in agricultural populations on cultivated oat in the United States. Phytopathology 94:505-514

25. Martin, C., and Thimann, K. V. 1972. The role of protein synthesis in the senescence of leaves. I. The formation of protease. Plant Physiol. 50:432-437.

26. Mendgen, K. 1984. Development and physiology of teliospores. Pages 375-398 in: The Cereal Rusts. W. R. Bushnell and A. P. Roelfs, eds. Academic Press, New York.

27. Osman-ghani, N. 1982. The uses and limitations of detached leaf culture for the assessment of reaction type in yellow rust of barley. Cereal Rusts Bull. 10:16-21.

28. Politowski, K., and Browning, A. J. 1975 Effect of temperature, light, and dew duration on relative numbers of infection structures of Puccinia coronata avenae. Phytopathology 65:1400-1404.

29. Portyanko, V. A., Chen, G., Rines, H. W. Phillips, R. L., Leonard, K. J., Ochocki, G. E., and Stuthman, D. D. 2005. Quantitative trait loci for partial resistance to crown rust, $P u c$ cinia coronata, in cultivated oat, Avena sativa L. Theor. Appl. Genet. 111:313-324.

30. Satler, O. S., and Thimann, K. V. 1983. Relation between respiration and senescence in oat leaves. Plant Physiol. 72:540-546.

31. Shibaoka, H., and Thimann, K. V. 1970. Antagonisms between kinetin and amino acids experiments on the mode of action of cytokinins. Plant Physiol. 46:212-220.

32. Simons, M. D. 1954. The relationship of temperature and stage of growth to the crown rust reaction of certain varieties of oats. Phytopathology 44:221-224

33. Staples, R. C. 2001. Nutrients for a rust fungus: the role of haustoria. Trends Plant Sci. 6:496-498.

34. Szabo, L. J., and Bushnell, W. R. 2001. Hidden robbers: the role of fungal haustoria in parasitism of plants. PNAS 98:7654-7655.

35. Takano, Y., Oshiro, E., and Okuno, T. 2001. Microtubule dynamics during infection-related morphogenesis of Colletotrichum lagenarium. Fungal Genet. Biol. 34:107-121.

36. Tetley, R. M., and Thimann, K. V. 1974. The metabolism of oat leaves during senescence I. respiration, carbohydrate metabolism, and the action of cytokinins. Plant Physiol. 54:294 303.

37. Wight, C. P., O'Donoughue, L. S., Chong, J., Tinker, N. A., and Molnar, S. J. 2004. Discovery, localization, and sequence characterization of molecular markers for the crown rust resistance genes $P c 38, P c 39, P c 48$ in cultivated oat (Avena sativa $\mathrm{L}$.). Mol. Breed. 14:349-361.

38. Zhu, S., and Kappler, H. F. 2003. Identification of quantitative trait loci for resistance to crown rust in oat line MAM17-5. Crop Sci. 43:358366. 